\title{
Abrupt Climate Change. An Alternative View
}

\author{
Carl Wunsch \\ Department of Earth, Atmospheric and Planetary Sciences \\ Massachusetts Institute of Technology \\ Cambridge MA 02139 USA \\ Email: cwunsch@mit.edu
}

November 15, 2005

\begin{abstract}
Hypotheses and inferences concerning the nature of abrupt climate change, exemplified by the Dansgaard-Oeschger (D-O) events, are reviewed. There is little concrete evidence that these events are more than a regional Greenland phenomenon. The partial coherence of ice core $\delta^{18} \mathrm{O}$ and $\mathrm{CH}_{4}$ is a possible exception. Claims, however, of D-O presence in most remote locations cannot be distinguished from the hypothesis that many regions are just exhibiting temporal variability in climate proxies with approximately similar frequency content. Further suggestions that D-O events in Greenland are a generated by shifts in the North Atlantic ocean circulation seem highly implausible, given the weak contribution of the high latitude ocean to the meridional flux of heat. A more likely scenario is that changes in the ocean circulation are a consequence of wind shifts. The disappearance of D-O events in the Holocene coincides with the disappearance also of the Laurentide and Fennoscandian ice sheets. It is thus suggested that D-O events are a consequence of interactions of the windfield with the continental ice sheets and that better understanding of the windfield in the glacial periods is the highest priority. Wind fields are capable of great volatility, very rapid global-scale teleconnections, are efficient generators of oceanic circulation changes and (more speculatively) of multiple states relative to great ice sheets. Connection of D-O events to the possibility of modern abrupt climate change rests on a very weak chain of assumptions.
\end{abstract}

\section{Introduction}

The widely-held view of abrupt climate change during the last glacial period, as manifested, particularly, in the so-called Dansgaard-Oeschger (D-O) events, is that they are at least hemispheric, if not global, in extent, and caused by changes in the ocean circulation. A version of the much disseminated curve that stimulated the discussion is shown in Fig. 1. 
The canonical view that ocean circulation changes were the cause of the abrupt changes seen in Greenland isotope records is widespread (e.g., Schmittner, 2005; Cruz et al., 2005) and is usually implied even where not explicitly stated. The possibility of abrupt climate change occuring because of the ongoing global warming and its oceanic effects is attracting great attention. For examples of how the hypothesis is influencing the debate about modern global warming, see Broecker (1997, 2003), or The Guardian, London (2005). Major field programs are underway seeking to see early signs of "collapse" of the North Atlantic circulation, e.g., the UK RAPID Program; see http://www.soc.soton.ac.uk/rapid/Scienceplan.php, with some anticipating the shutoff of the Gulf Stream (Schiermieir, 2004).

Given the implications for modern public policy debate, and the use of this interpretation of D-O events for understanding of past climate change, it is worthwhile to re-examine the elements leading to the major conclusions. Underlying the now very large literature of interpretation are several assumptions, assertions and inferences including:

(1) The $\delta^{18} \mathrm{O}$ variations appearing in the record of Fig. 1 are a proxy for local temperature changes.

(2) Fluctuations appearing in Greenland reflect climate change on a hemispheric, and probably global, basis and of large amplitude.

(3) The cause of the D-O events can be traced back to major changes (extending to "shutdown") of the North Atlantic meridional overturning circulation and perhaps even failure of the Gulf Stream.

(4) Apparent detection of a D-O event signature at a remote location in a proxy implies its local climatic importance.

The purpose of this paper is to briefly re-examine these assumptions and assertions, but with emphasis on (2) and (3). A summary of the outcome of the survey is that (1) is in part true; little evidence exists for (2) other than a plausibility argument; and (3) is unlikely to be correct. Inference (4) can only be understood through a quantitative knowledge of controls of local proxies, and is briefly likened to the problem of interpreting modern El Niño signals. The paper ends with a discussion of how to move forward.

\section{The Connection of $\delta^{18} \mathrm{O}$ to Local Temperature}

D-O events were initially observed in $\delta^{18} \mathrm{O}$ fluctuations in the Greenland ice cores (e.g., Dansgaard, 1987). $\delta^{18} \mathrm{O}$ is an atmospherically transported tracer field undergoing fractionation. Jouzel et al. (1997) have reviewed many of the elements of the complicated determinants of the deposition values of $\delta^{18} \mathrm{O}$ and of the corresponding anomaly ratios for deuterium $(\delta \mathrm{D})$. The 
ratio of the concentrations of the isotopes of oxygen $\left({ }^{18} \mathrm{O},{ }^{16} \mathrm{O}\right)$ in the Greenland ice cores are frequently interpreted as reflecting the temperature of deposition, although it has long been noted that this relationship is at best an approximation (e.g., Jouzel et al, 1997; Friedman et al., 2002). In recent years, a number of papers (Severinghaus et al. (1998), Severinghaus and Brook (1999), and Landais et al. ( 2004)) have compared the time rates of change of temperature to those inferred from measurements of the in situ fractionation of argon and nitrogen isotopes in the cores. Under the assumption that the latter are essentially perfect determinants of temperature rate of change, Landais et al. (2004), for example, conclude that $\delta^{18} \mathrm{O}$ is, within a time-varying factor of two, a reflection of local temperature at the deposition site. The $\delta^{18} \mathrm{O} /$ temperature relation is strong, but apparently not simple. For present purposes, we can stipulate that Fig. 1 approximately depicts rapid temperature changes in central Greenland.

\section{Spatial Scale of D-O Events}

A very large literature exists showing alignments of features in the Greenland ice core records with various proxy variations at varying distances. Alignments have been done with data from the Cariaco Basin, the Santa Barbara Basin (California), Hulu Cave (eastern China), the western Mediterranean, the North Atlantic, as well as many other places. The major issue with these comparisons is the tendency for unrelated records having similar frequency content to necessarily display a similar "wiggliness" (Wunsch, 2003a). Required visual similarity can be understood by noting that the statistics of record crossings of the mean or other level are dependent only upon the low moments of the spectral densities. Spectral densities are descriptions of the record energy content as a function of frequency. The probability of record extrema (positive or negative) per unit time is also closely related to the threshold crossing problem ("Rice statistics"). Cartwright and Longuet-Higgins (1956) is a standard reference, and a summary can be found in Vanmarcke (1983). Specifically, for zero-mean Gaussian processes, the average rate of zero crossings (either upward or downward) depends only upon the first two moments, $\lambda_{i}$, of the spectral density, $\Phi(\omega)$, with,

$$
\lambda_{k}=\int_{-\infty}^{\infty}|\omega|^{k} \Phi(\omega) d \omega, \quad k=0,1,2, \ldots .
$$

\{moments1\}

and $\omega$ is the radian frequency. In particular, the expected rate with which the time series crosses zero headed upwards (or downwards) is $1 / 2 \pi \sqrt{\lambda_{2} / \lambda_{0}} /$ unit time. So Gaussian time series with near-identical spectral shapes will have near-identical moments, and thus rates of zero crossings, and of associated positive and negative extremes. The requirement is actually very weak - only the ratio of the integrals in (1) for small $k$ have to be about the same. For non-Gaussian processes (e.g., Larsen et al., 2003), the same effect occurs, albeit the quantitative rates of zero-crossing 
will differ. Even completely indepenent physical processes with similar $\lambda_{k} / \lambda_{0}$ are guaranteed to display a high degree of visual correlation. That only the moment ratio appears shows that the zero-crossing rate is independent of the absolute spectral level and measurement units..

The major problem in tuning or wiggle-matching is that of "false-positives" - the visual similarity between records that are in truth unrelated. A good deal is known (e.g., Barrow and Bhavsar, 1987; Newman et al., 1994) about the tendency of the human eye to seek, and often find, patterns in images that are tricks of the human brain. (The classical example is the conviction of a large number of astronomers that they could perceive "canali" or lines, on the Martian surface.) A related problem is the tendency to attribute importance to rare events that occur no more often than statistics predicts (e.g., Kahneman et al., 1982; Diaconis and Mosteller, 1989). It is for this reason that statisticians have developed techniques for determining the significance of patterns independent of the human eye.

An example of the problem is shown in Fig. 2. The black curve represents the three-month running average of monthly maximum temperature in Oxford, UK between 1861 and 1903, and the red curve is the same physical variable, but between 1936-1978 (the annual cycle having been suppressed). This arbitrary example was chosen because it is a simple way of obtaining two real physical records with nearly identical spectral densities, but for which there is no plausible mechanism by which they should be correlated or coherent. The "event" in the black record in 1880 might be identified with the weaker minimum occurring in the gray curve just slightly "earlier," and some physical hypothesis for the delay, or for age-model alignment, made. More generally, if there were some uncertainty of the age-models for these two records (there isn't any), one might be strongly tempted to argue that the degree of alignment that can be achieved by comparatively small age-model adjustments is too great to occur by chance. But, here it does occur by chance, and is a direct consequence solely of the common frequency (spectral) content.

Another example of visually similar, but unrelated, processes would be the behavior of midlatitude weather variations e.g., in mid-continental Asia and mid-continental North America: there may even be some real (small) correlation among temperature, precipitation etc., but few would claim that aligned maxima or minima demonstrate a causal relationship. Other examples abound: oceanographic ones are the internal wave or mesoscale eddy bands at similar latitudes. Whether glacial advance/retreat similarities between distant locations reflect causal relationships, or only common underlying physics producing similar patterns of maxima and minima, would have to be determined. In any event, in comparing two records and in claiming identity of events, an important point is that alignment failures are just as significant, overall, as are their correspondences.

Consider now Fig. 3 showing a green-band reflectance time series from the Cariaco Basin 
(Peterson et al., 2000), as aligned subjectively by those authors, with the GISP2 ice core. Reflectance change is thought to be related to a combination of local rainfall and biological productivity, and which in turn are supposed to be related to climate change in an unspecified way. The coherence between these records is displayed in Fig. 4. Despite the alignment, there is no statistically significant coherence between the records at periods shorter than about 900 years. Such a result does not disprove the hypothesis of large spatial extent of the D-O events, but the record, showing no high frequency covariance, cannot be used to support the inference - it remains possible, but not demonstrated. (The abrupt nature of D-O events means that they are necessarily rich in high frequencies.) The visual alignments apparently depend primarily upon the more energetic low frequency structures, rather than upon the high frequencies, and the lower frequencies are not readily related to D-O events.

Visually, there are features in the two records, as adjusted, that are strikingly similar, including the Younger Dryas at about -12kyr, and the shifts occurring at about $-72,-84 \mathrm{kyr}$, but many other features appear to be unique to one or the other record (e.g., during the Holocene; the Cariaco maxima near -60kyr; and one just prior to the YD.) Beyond that, all one can really say is that both records exhibit a rich high frequency variability and the records are not best described on average as showing similar features. As already noted, one can attempt, within the age uncertainties, to shift the records so that extreme variations coincide, as has been done in the figure. This result is then an assumption, not an inference. (A general discussion of the problems of developing chronologies under uncertainty can be found in Buck and Millard, 2004.)

Estimated power densities of the Greenland and Cariaco records (after adjustment) shown in Fig. 5 are similar, but not identical, and will have similar second moments, which determine the rate of zero-crossings and hence average number of maxima and minima within any finite time interval. Spectral moments (Eq. 1) have some sensitivity to the high frequency cutoff, as high frequencies are given increasing weight with moment number. If the integrals are stopped at about 1 cycle/100yr, the ratios $\sqrt{\lambda_{2} / \lambda_{0}}$, which control the zero crossing rates, are $\sqrt{3.2}$, $\sqrt{3.5}$ respectively for reflectance and $\delta^{18} \mathrm{O}$. At the high frequency end, the excess energy in the GISP2 record relative to the Cariaco Basin may well arise from the high frequencies necessary to produce the abrupt changes of the D-O events. It is also potentially an artifact of sampling, including the likelihood of aliasing in the records (see, e.g., Wunsch and Gunn, 2002). Rates of maximum and minimum appearance per unit time depend upon $\lambda_{4}$ (Vanmarcke, 1983, Eq. 4.4.7) and will be more sensitive to the nature of the high frequency cutoff.

The disappearance of any coherence at periods shorter than about 900 years has at least three explanations: (1) Although both records have a physically rich variability, it is primarily regional in character and there is no simple relationship between them. This interpretation 
would be similar to that describing, e.g., London UK and New York City daily temperature variations. (2) The age-model error has a larger influence on the short-period variations than on the long-period ones (consistent e.g., with the analytical results of Moore and Thomson, 1991, and Wunsch, 2000) and destroys what would otherwise be a strong coherence. (3) Different physical processes dominate the proxies at high frequency in the Cariaco Basin and Greenland, but they have roughly similar low spectral moments. On the basis of these two records, one cannot distinguish these explanations and all three may well be operating.

Analyses similar to that of Peterson et al. (2001) have been carried out for the Arabian Sea (Schulz et al., 1998), the Santa Barbara Basin (Hendy et al., 2002), and Hulu Cave near Nanjing, China (Wang et al. 2001) among numerous other locations. Figs. 6 displays Hulu cave results whose timing is believed relatively accurate, and showing the visual identification by Alley (2005) of supposed corresponding events in Greenland and in China. The Santa Barbara Basin $\delta^{18} \mathrm{O}$ record is shown in Fig. 7. It is left to the reader to decide if the records are showing common events or possibly only similar spectral moments.

Little direct support, by objective measure, is found for the hypothesis that abrupt changes in Greenland also appear in these other records. There is clear evidence of low frequency (periods of thousands of years) coherence, and the occasional near-alignments of short period events appear very suggestive. But many other short period events do not appear in the paired records. The hypothesis that there exist large-scale hemispheric correlations of the D-O events remains neither proven nor (within the age-model errors) disproven.

There is a caveat to the above discussion. The results represent average behavior over the entire records (a conventional analysis starting point), and which are dominated by the glacial interval. It is entirely possible that during periods of strong disequilibrium, such as the major deglaciation, the system behaves very differently than it does in the glacial or Holocene periods. Thus no inference is drawn here about the spatial extent of special events during the deglaciation (viz., the Younger Dryas), which are not necessarily typical of the record as a whole.

A different argument for the spatial extent of $\mathrm{D}-\mathrm{O}$ events can be made by the coincidence, with comparatively little relative timing error, in the GISP2 record of some D-O events with excursions in methane concentration there (e.g., Blunier and Brook, 2001). Glacial-period methane sources are supposedly controlled largely by tropical wetlands, and to the extent that those regions are showing strong correlation with D-O events in Greenland, one infers that there is at least a hemispheric reach. There are two issues here: (1) Whether methane sources (and sinks) are definitively tropical, and, (2) the actual correlation in Greenland of methane and $\delta^{18} \mathrm{O}$ (See Fig. 8).

The first issue is discussed by Chappellaz et al. (1993) who place most of the modern 
wetlands at high latitudes, and most during the last glacial maximum at low latitudes. How wetlands would have behaved during regional warm events lasting of order 1000 years is not so clear, nor is the extent to which a large-scale high latitude meteorological shift would influence frozen wetlands during the glacial period. (Wetlands are the dominant, but by no means the only, source of methane; Chappelaz, et al., 1993; potential changes in methane sinks would also come into play.)

The second issue can be analyzed more directly. In the time series seen in Fig. 8, some, but far from all, of the extreme events visible in the $\delta^{18} \mathrm{O}$ curve are apparent in the $\mathrm{CH}_{4}$ record. To quantify their behavior, Fig. 9 shows power density and coherence estimates for the records in Fig. 8. Significant coherence at a level of about 0.7 (accounting for about $50 \%$ of the variance) exists at periods longer than about 400 years. This result suggests that some of the D-O events are indeed correlated with methane emissions, but the evidence that it results from a strong, remote, tropical response remains unquantified. Nonetheless, the methane $\delta^{18} \mathrm{O}$ correlation is the strongest evidence that the D-O events reach to low latitudes, albeit the inference depends upon the scanty knowledge of the methane sources and sinks during these times. (Note that Wunsch, 2003a, found that coherence in the methane signals between the Antarctic Byrd core and Greenland did not extend to periods shorter than about 1300 years. Whether the failure to find shorter period coherence occurs because local sources dominate the Greenland record, or because of ice/air age model or other errors, is unknown.) If it can be shown, e.g. through isotopic differences between high and low-latitude wetlands sources, that methane emission is primarily under low-latitude control, that would be strong evidence that the D-O events have significant effects beyond the neighborhood of Greenland.

In a more general sense, one must distinguish between climate phenomena whose (a) trigger regions, (b) foci of strongest signal, and (c) regions where a signal is detectable, may each be radically different. For example, modern El Niño is primarily a tropical Pacific Ocean phenomenon, but generates detectable signals at great distances in latitude and longitude. The extent to which it is generated in the oceanic tropics, as oppposed e.g., to being largely governed by stochastic westerly wind bursts of continental origin, is the subject of great debate (e.g., Neelin et al., 1998). Thus for D-O events, even the detectability of a signal remotely need not lead to a deduction of its local importance, nor to inferences about generation - a subject taken up next. 


\section{North Atlantic Circulation Control}

Our focus now changes to the separable issue of cause (or "trigger") of the rapid changes seen in central Greenland. Consider now the widely accepted scenario that Greenland D-O events are a direct consequence of a major shift in the North Atlantic meridional overturning circulation. Some confusion occurs at the outset because of a failure to specify which elements of that circulation are supposed to generate the climate change (Wunsch, 2003b) . Often the focus is on the mass flux associated with the meridional overturning, and the mass flux is indeed central to the dynamics of the ocean. But in terms of the impact on the climate system, it is the oceanic poleward heat flux that has the most immediate consequences for the atmosphere. Alternatively, seasurface temperatures are most often used to determine how the ocean is affecting the atmospheric state, although these will be in large part a consequence of the heat flux divergence (exchange of enthalpy with the atmosphere).

Fig. 10 displays the estimated net meridional transport of heat by the combined ocean/atmosphere system, as well as separate estimates of the oceanic and atmospheric contributions (Wunsch, 2005). A number of features stand out in this figure. First, the oceanic northern hemisphere contribution poleward of about $25^{\circ} \mathrm{N}$ falls very rapidly as heat is transferred to the atmosphere through the intense cyclogenesis in the mid-latitude storm belts, and as the relative oceanic area rapidly diminishes. By $40^{\circ} \mathrm{N}$, the oceanic contribution is less than $25 \%$ of the atmospheric contribution. Of this 25\%, most is in the North Atlantic (e.g., Ganachaud and Wunsch, 2002). The assumption that a fractional change in this comparatively minor contribution to the global heat flux is the prime mover of abrupt climate change is not very appealing - if there is any alternative possibility (one will be proposed below). Furthermore, air mass trajectories circling the globe at high latitudes are in contact with the North Atlantic Ocean for only a very short time compared to the North Pacific, Asia and North America. The oceanic tail may not necessarily be wagging the meteorological dog.

Second, note that within the significant error bars, the "conveyor" (the real "global conveyor" is the combined ocean and atmospheric transport) is indistinguishable from being antisymmetric about the equator. The net oceanic transport is asymmetric about the equator, with the atmospheric contribution compensating within observational error. An overall anti-symmetry, despite the asymmetry of the separate oceanic and atmospheric fluxes, is one of the more remarkable, but hardly noted, elements of the modern climate system. Stone (1978) discusses some of the physical elements controlling the total fluxes.

If this anti-symmetry is maintained as the climate system shifts (assuming the modern antisymmetry is not mere accident), a reduction in the northern hemisphere oceanic heat transport 
would be compensated by a corresponding increase in the atmospheric transport. That is, on a zonally integrated basis, one plausible outcome of a hypothetical "shutdown" of the North Atlantic overturning circulation, with any consequent reduction in oceanic heat transport, is a warmer (and/or wetter) northern hemisphere atmosphere rather than a colder one. This argument says nothing at all about a regional atmospheric cooling in the North Atlantic sectoronly that should it occur, it would have to be compensated elsewhere so as to maintain the balance of incoming and outgoing radiation. Claims that it is obvious that the North Atlantic sector atmosphere must cool are difficult to sustain. (How the tropics, and e.g., its albedo, might shift through all of this, are unspecified in most discussions.)

Setting the global problem aside, turn now to the question of how a hypothetical North Atlantic meridional overturning circulation shutdown would occur. The conventional explanation connects it to a strong decrease in surface salinity from melting glacial ice. The hypothesis is that an injection of fresh water would dramatically reduce the meridional overturning circulation (MOC) - that is the zonally integrated mass flux. An extensive literature (e.g., Manabe and Stouffer, 1999) has collected around this hypothesis and it has been the focus of numerous modeling efforts as well as being presented as "fact" to the public. Despite its intuitive appeal, there are a number of serious difficulties with it. That fresh water injection controls the North Atlantic circulation can be questioned from several points of view. First, existing climate models, which are the main tool that have been used to study the hypothesis, do not have the resolution, either vertical or horizontal, to properly compute the behavior of fresh water and its interaction with the underlying ocean and overlying atmosphere. Models of the modern ocean contain special, high resolution subcomponents designed to calculate mixed layer behavior (e.g., Price et al., 1986; Large et al., 1994). Despite the great effort that has gone into them, systematic errors in calculating mixed layer properties remain. How these errors would accumulate in climate-scale models, with much less resolution is unknown. Second, some models also use a physically inappropriate surface boundary condition for salinity, leading to serious questions about the physical reality of the resulting flows (Huang, 1993).

Third, the models have almost always been run with fixed diffusion coefficients. Recently, a series of papers (Munk and Wunsch, 1978; Huang, 1999; Nilsson et al., 2003; Wunsch and Ferrari, 2004) have noted that, (a) mixing coefficients have a profound influence on the circulation; (b) fixed mixing coefficients as the climate system shifts and/or as fresh water is added, are very unlikely to be correct; (c) depending upon exactly how the mixing coefficients are modified, fresh water additions can actually increase the North Atlantic mass circulation (Nilsson et al., 2003). Finally (d), the prime mover of the ocean circulation, including its mixing coefficients as well as providing the major direct input of energy (Wunsch and Ferrari, 2004) is the wind. If one 
wishes to change the ocean circulation efficiently and very rapidly, all existing theory points to the wind field as the primary mechanism. Scenarios that postulate shifts in the ocean circulation leading to major climate changes (e.g. D-O events), imply important changes in the overlying wind field in response, with a consequent feedback (positive or negative). It is extremely difficult to evaluate proposals that the climate shifted owing to a "shutdown" of the MOC if no account is taken of how the overlying atmospheric winds would have responded. In any event, much of the temperature flux of the modern North Atlantic is carried in the Gulf Stream; scenarios requiring wind shifts sufficient to shut it down are likely a physical impossibility because of the need to conserve angular momentum in the atmosphere. Apparent correlations of the Greenland $\delta^{18} \mathrm{O}$ shifts with possible corresponding events in North Atlantic deep-sea cores (e.g., Bond et al., 1993) are rationalized most directly as reflecting oceanic circulation changes induced by moderate, acceptable, changing wind stress fields.

Coupled models that have been claimed to show atmospheric response to oceanic mass flux shifts do not themselves resolve the major property transport pathways of either ocean or atmosphere. Some of these models are of the "box" form, with as few as four parameters. More sophisticated models are commonly described as "intermediate complexity" ones; despite the label, they still lack adequate resolution and dynamical and physical components required for true realism. Little evidence exists that such simplified representations of the climate system can be integrated skillfully over the long periods required to describe true climatic time scales as both systematic and random errors accumulate. Whether dynamical thresholds in oversimplified models correspond to those in the enormously higher dimension real system also remains unproven. Combined with the resolution issue, one concludes that as yet, modeling studies neither support nor undermine the canonical scenario. They remain primarily as indicators of processes that can be operating, but with no evidence that they dominate. ${ }^{1}$

Furthermore, there is no known simple relationship between the zonally integrated overturning stream function defining the MOC, and either the heat flux or the seasurface temperatures. Even if the MOC did weaken, there is no logical chain leading to the inference that the seasurface temperatures must be reduced (although in some models, they are reduced).

\footnotetext{
${ }^{1} \mathrm{~A}$ reviewer questions the assertion that models necessarily accumulate errors. Probably the earliest timestepping models were those used for calculating planetary and cometary positions (Gauss, and many others). They recognized from the outset that as their calculations were carried forward in time, estimated future positions would become increasingly erroneous. This result has nothing to do with chaos, but with simplified models and initial condition errors. Many such errors are bounded (asimuthal errors cannot exceed $180^{\circ}$ of arc, no matter how poor the model), but any claim to model skill must estimate the size of the inevitable errors incurred relative to the signals sought. The only clear conclusion is that such errors never vanish, although they might be, demonstrably, small.
} 
Much of the evidence for "shutdown" deals with elements of the circulation that do not directly imply anything about shifts in heat flux or seasurface temperature. Some of the inference concerns the net export of properties from the North Atlantic (e.g., Yu et al., 1996 for protactinium). But in the modern system (e.g., Ganachaud and Wunsch, 2002), estimation of the mean meridional property transport depends upon the property (temperature, oxygen, etc.) and the ability to calculate the integral of velocity times property concentration as a function of longitude and depth across the entire ocean basin. That is, the net meridional property flux is,

$$
H_{C}=\int_{0}^{L} \int_{z_{b}(x)}^{0} \rho(z, x) v(z, x) C(z, x) d z d x .
$$

Here, $z, x$ are vertical and zonal coordinates respectively, $z_{b}(x)$ is the bottom topography, and $\rho$ is the density, assuming $C$ is given as units/unit mass. $L$ is the zonal ocean width. Fixed $\rho v$ (mass flux distribution) produces some properties that are imported on average into the North Atlantic (temperature or enthalpy), and some that are exported (e.g., nitrate, oxygen). The sign of $H_{C}$ depends upon the particular property, and net transports are the result of a spatially complex covariance between the mass flux, $\rho v$, and the concentration $C$. Fig. 11 displays an estimate for the absolute North Atlantic meridional flow at $7.5^{\circ} \mathrm{N}$ as obtained by Ganachaud (1999). Its computation necessitates, among other issues, accurately representing the high speed boundary currents, their property concentrations, and their recirculating exchanges with the interior; these are unresolved in existing climate models. Assertion that total import/export of a particular tracer, $C$, for example, protactinium, increased or decreased from the North Atlantic provides a useful integral constraint on a model, but carries only slight information about the structure of $\rho(z, x) v(z, x)$, especially so when the spatial structure of $C(z, x)$ is itself unknown.

Other paleo evidence (e.g., Boyle, 1995; Curry and Oppo, 2005) strongly supports the inference that the high latitude distribution of water masses has shifted through time- unsurprising in an ocean with a radically different overlying atmospheric state. The simplest, and widely accepted, interpretation of much of the data is, for example, that during the Last Glacial Maximum, the equivalent of North Atlantic Deep Water shifted upward in the water column. Displacement of a water mass and a change in its defining properties carries no information about changes in either its mass flux or temperature transport properties: they could separately or together increase, decrease or remain unchanged. Indeed, the export of some properties could increase and some simultaneously decrease - without any contradiction. If, as is widely believed, the North Atlantic Deep Water migrated upwards, its southward cold temperature transport could actually have increased if its mass flux increased correspondingly (no evidence exists). Furthermore, because $H_{C}$ involves an integral over the entire water column, one also needs to understand the changes in properties and mass fluxes of all of the water masses making up the 
North Atlantic. Specific attention (e.g., Wunsch, 2003b) is called to the question of whether the southern component waters, with their extreme properties, were not more actively present in the North Atlantic during this time, probably because of an intensified, not a weakened, circulation. One cannot calculate oceanic heat fluxes without specifying a complete oceanic cross-section mass flux and temperature distribution. ${ }^{2}$

Postulate, however, that the scenario of a weakened MOC requires a reduced air/sea transfer of heat in the North Atlantic. What will the atmosphere do? The net outgoing radiation must balance the incoming, and so compensation for a reduced ocean heat transport must occur. It can occur by increasing the ocean heat transport somewhere else (the North Pacific?) with consequent changes in atmospheric circulation, or by having the atmosphere compensate, as it seems to be doing in Fig. 10, or by quite different changes elsewhere (increased tropical albedo, for example). Will the northern hemisphere atmosphere warm on average? It seems foolhardy to speculate further at this time. What does seem clear is that the hypothesis of a reduced North Atlantic MOC produces at best a regional story, one whose global implications have to be determined using convincing global data and models.

\section{An Alternative View}

Fig. 1 and the supporting evidence from Ar and $\mathrm{N}$ described above makes it highly plausible that central Greenland temperatures underwent abrupt shifts, although the magnitude of the shifts is subject to uncertainty within time-varying factors of about two. As we have seen, evidence for the existence of the D-O events elsewhere remains ambiguous (neither proven nor dis-proven). This inference suggests at least examining the climate system for explanations directed at the central Greenland shifts, without necessarily having to explain simultaneous shifts everywhere else (although we will return to that problem later).

Examination of Fig. ?? shows in addition to the striking D-O events, several other very interesting features, but we here call attention to only one of them - the disappearance of the Greenland D-O events in the Holocene, approximately the last 10,000 years of the record, and its remarkable placidity since then. (In contrast e.g., to the behavior during the Holocene of the Cariaco reflectance curve.) If one takes this disappearance as a clue to the operative mechanisms,

\footnotetext{
${ }^{2}$ Physical oceanography would be a very different subject if there were any known relationship between water mass volumes and distributions, and the rates of flow. Classical oceanographers such as G. Wüst struggled without success to connect ideas such as the "core-layer" method to inferences about water mass fluxes. Most of what today is known of rates of water mass movement of necessity relies upon geostrophic calculations, that is, detailed knowledge of the vertical and horizontal density gradients throughout the volume are used to compute water velocities.
} 
it leads one to ask what was the major change between the glacial period and the Holocene? The answer is, of course, immediate - it is the disappearance of the Laurentide and Fennoscandian icesheets. In effect, two enormous mountain ranges of high albedo, nearly bracketing Greenland, were removed. When these features are present, D-O events are observed. When they are absent, D-O events are also absent. For context, Fig. ?? shows Peltier's (1994) estimate of the ice sheets surrounding Greenland as the deglaciation proceeded.

This observation leads one to ask how the presence of the ice sheets could conceivably be responsible for the D-O events? There are a few clues. Jackson (2000) studied the interaction of a one-layer atmospheric model and the Laurentide ice sheet topography. He demonstrated that small regional changes in the ice sheet elevations had a large effect on the atmospheric stationary wave patterns. Roe and Lindzen (2001) calculated the influence of an idealized Laurentide ice sheet on the atmospheric circulation, including modification of the ice sheet itself by the atmospheric circulation. A reasonable inference is that the mean structure of the westerly wind system, the standing-wave patterns, encountering the massive ice sheets is quite different from its modern value, and that more than one equilibrium is possible. Figs. ??-?? show a reference standing wave pattern in the absence of an ice sheet, a disturbance ice sheet with which the westerlies can interact generating feedbacks, and the perturbation to the standing wave pattern that results in one configuration. Major local climate change could appear, e.g., even if the dominant wavenumber of the zonal standing wave pattern only shifted by $90^{\circ}$ with no change in the wavenumber itself. Whether there are truly multiple states, with prevailing winds shifting north and south of the Laurentide and Fennoscandian ice sheets, is not so clear, but as an hypothesis it has its attractions.

Earlier modeling calculations such as that of Kutzbach and Guetter (1986) are strongly suggestive, as they slowly changed the shape of the Laurentide and Fennoscandian ice sheets, of their influence on the climate system. The models used were, however, of very coarse resolution relative to the ice sheet and North Atlantic structures. A very recent report (Justino, et al., 2005) suggests the great influence of the ice sheets on atmospheric synoptic scales, but their model lacked the ability for the climate to modify the ice sheets. High resolution models with detailed land ice/atmosphere/seaice/ocean feedbacks are required for realistic depiction of potential abrupt atmospheric circulation shifts.

In a more abstract context, Farrell and Ioannou (2003) have shown that the equilibrium position for a zonal jet can be quite sensitive to the underlying boundary conditions, including albedo. It is suggested, therefore, that an attractive physical mechanism for explaining the D-O events and corresponding signals around the world including the open ocean, is a shift in the pattern (phase) of atmospheric stationary waves owing to interactions with the Laurentide and 
Fennoscandian ice sheets. That is, even such an apparent minor atmospheric changes as a $90^{\circ}$ phase shift in the pattern of mean westerlies encountering Greenland would markedly change the temperature and precipitation patterns there, as well as induce a change in the wind-stress curl over the ocean to the south. (See Wunsch, 2003b for a more detailed discussion of the behavior of the Greenland ice core record under this hypothesis.) The modification and removal of the great continental ice sheets corresponds to changes in a huge orographic feature. These changes seem at least as compelling as a candidate for generating abrupt, regional, climate change as is the comparatively modest oceanic heat flux that has been so widely discussed.

How does this approach to rationalization deal with what may be remote indicators of D-O events both on land, and suggestions of oceanic changes? The conventional theory of the ocean circulation (e.g., Pedlosky, 1996) represents the three-dimensional motions in terms, primarily, of the windstress driving. Energy arguments (e.g., Munk and Wunsch, 1998; Huang, 1999; Wunsch and Ferrari, 2004) show that buoyancy forcing, while contributing in important ways to the structure of the circulation and determining to a large degree the extent to which it carries heat and moisture, cannot "drive" the circulation in any conventional sense. ${ }^{3}$ The body of theory suggests that the most important and sensitive determinant of the circulation is the wind field. Any change in the high latitude North Atlantic wind field, even without more remote changes, would lead one to anticipate very rapid shifts in the ocean circulation patterns, and with a record of these changes appearing in the sediments. That is, one expects the ocean to promptly respond, possibly as seen in the Bond et al. (1993) high latitude North Atlantic records. Coupled with amplifiers in the form of sea ice feedbacks (e.g., Li et al., 2005) the ocean would surely be a significant, if not a dominant, element in whatever climate change occurred.

\section{Discussion}

The observational record supports at least one alternate interpretation of the D-O events as being primarily a central Greenland phenomenon, dependent for their existence upon the Laurentide and Fennoscandian ice sheets. A possible exception to this inference lies with the methane record of the Greenland ice cores, but the interpretation rests upon the sketchy knowledge of the behavior of glacial-period methane source and sink distributions. The primarily local interpretation implicates the wind field as the central element by which central Greenland temperatures change abruptly, and the mechanism by which larger-scale signatures would be carried to distant locations, including those induced by ocean circulation shifts under the changing wind system.

\footnotetext{
${ }^{3}$ The word "drive" is used in the sense of the forces providing the requisite energy. One should distinguish "drivers" in this sense, from their colloquial use to denote human "controllers," as in automobiles.
} 
Given the comparatively small contribution of the ocean to the high latitude meridional flux of heat, it seems an unlikely primary stimulus of major climate shifts beyond the North Atlantic basin. It can readily operate as an integrator and as a transmitter of signals, but that is a different role.

Like the widely accepted view, this reinterpretation has not been demonstrated. But maintenance of an open mind is important when the data are so ambiguous. Several steps can be taken to reduce the uncertainty about how the $\mathrm{D}-\mathrm{O}$ events were generated and manifested. The most important parameters, wind-direction and speed through time, may be beyond reach of the proxy record. But perhaps the search for such proxies will be rewarded (dust, sand dunes, pollen distributions). The question of the spatial extent and intensity of D-O events can be addressed by continuing efforts to reduce age model uncertainties. Existing oceanic ${ }^{14} \mathrm{C}$ dates have an approximate uncertainty of \pm 300 years, with a multi-valued structure, through much of this period - sufficiently wide that great freedom is available in adjusting records to apparently coincide. Interpretation of the methane signature in ice cores would be greatly strengthened by better understanding of how, and how rapidly, wetlands evolve under glacial conditions, and particularly with an ability to distinguish low and high latitude sources. Other gases detectable in ice cores (e.g., $\mathrm{N}_{2} \mathrm{O}$; see Flückiger et al., 2004) might, if there is adequate knowledge of the changing source/sink distributions, shed light on the spatial extent question. The presence in other proxies of signals, perhaps convincingly, corresponding to remote manifestations of D-O events need, however, to be intrepreted very cautiously - as they may be no more than measurable signals not corresponding to important local climate shifts: the analogy is drawn with remote detectability of modern Los Niños. (One might detect El Niño signals over central Asia; they may not be of any importance.)

Modeling efforts, with sufficient spatial resolution to respond to shifts in the ice orography, and to produce realistic feedbacks, as begun by Jackson (2000) and Roe and Lindzen (2001), would be very informative. If interactions do not produce atmospheric flows exhibiting sustained multiple state shifts in the hemispheric standing wave patterns, then the hypothesis proposed here would be less attractive. Existing models are unlikely to have adequate skill when integrated over the thousands of years required to understand D-O type events, given the propensity, as the duration of the computation increases, of all models to accumulate random and systematic errors. Finally, a better understanding of how the global ocean and atmosphere conspire to maintain outgoing radiation sufficient to balance the incoming component would be very helpful in understanding how the coupled system actually behaves.

Acknowledgements. I had very useful comments from P. Huybers, J. Sachs, and J. Severinghaus, without necessarily implying their agreement with everything here. The input of E. Steig 
was invaluable. I thank G. Roe for electronic versions of his figures. Supported in part by the National Ocean Partnership Program (NOPP). 


\section{References}

Alley, R. B., 2005. Abrupt climate changes, oceans, ice, and us. Oceanography, 17, 194-206.

Barrow, J. D. and S. P. Bhavasar, 1987. Filaments: what the astronomer's eye tells the astronomer's brain. Q. J. Royal Astronom. Soc., 28, 109-128.

Blunier and Brook, 2001

Buck, C. E. and A. R. Millard (Eds.) 2004. Tools for Constructing Chronologies. Crossing Disciplinary Boundaries 257 pp. Springer-Verlag, London.

Bond, G., W. Broecker, S. Johnsen, J, McManus, L. Labeyrie, J. Jouzel, and G. Bonani, 1993. Correlations between climate records from North Atlantic sediments and Greenland ice. Nature, 365, 143-147.

Boyle, E., 1995. Last-Glacial Maximum North Atlantic Deep Water: on, off or somehere in-between. Phil. Trans. R. Soc. Lond. B., 348, 243-253.

Broecker, W. S., 1997. Thermohaline circulation, the Achilles heel of our climate system: Will man-made CO2 upset the current balance? Science, 278, 1582-1588.

Broecker, W. S., 2003. Does the trigger for abrupt climate change reside in the ocean or in the atmosphere? Science, 300, 1519-1522.

Cartwright, D. E. and M. S. Longuet-Higgins, 1956. The statistical distributions of the maxima of a random function. Proc. Roy. Soc., A, 237, 212-232.

Chappellaz, J. A., I. Y. Fung, T. L. Kucsera, 1993. The atmospheric CH4 increase since the Last Glacial Maximum. Tellus, 45B, 228-241.

Cruz, F. W., Jr. and eight others, 2005. Insolation-driven changes in atmospheric circulation over the past 116,000 years in subtropical Brazil. Nature, 434, 63-66.

Curry, W. B. and W. B. Oppo, 2005. Glacial water mass geometry and the distribution of $\delta^{13} \mathrm{C}$ and $\sum \mathrm{CO}_{2}$ in the western Atlantic Ocean. Paleoceanog., 20, PA1017, doi:10.1029/2004PA001021.

Dansgaard, W., 1987. Ice core evidence of abrupt climatic changes. in, Abrupt Climatic Change. Evidence and Implications, W. H. Berger and L. D. Labeyrie, eds., D. Reidel, Dordrecht, 223-233.

Diaconis, P. and F. Mosteller, 1989. Methods for studying coincidences. J. Am. Stat. Assoc., 84, 853-861.

Farrell, B. F. and P. J. Ioannou, 2003. Structural stability of turbulent jets. J. Atm. Scis., 60, 2101-2118.

Flükiger, T. Blunier, B. Stauffer, J. Chappella, R. Spalini, K. Kawamura, J. Schwander, T. F. Stocker, and D. Dahl-Jensen,2004. $\mathrm{N}_{2} \mathrm{O}$ and $\mathrm{CH}_{4}$ variations during the last glacial epoch: insight into global processes. Global Biogeochem. Cycles, 18, GB1020, doi:10.1029/2003GB002122. 
Friedman, I., G. I. Smith, C. A. Johnson, and R. J. Moscati, 2002. Stable isotope compositions of waters in the Great Basin, United States - 2. Modern precipitation. J. Geophys. Res.-Atmospheres, 107(D19), Article No. 4401.

Ganachaud, A., 1999. Large Scale Oceanic Circulation and Fluxes of Freshwater, Heat, Nutrients and Oxygen. PhD Thesis, MIT/WHOI, 266pp.

Ganachaud, A. and C. Wunsch, 2002. Large-scale ocean heat and freshwater transports during the World Ocean Circulation Experiment. J. Clim., 16, 696-705.

Guardian, The, London, 2005. Hotter world may freeze Britain. The Guardian, London, 2 February 2005 article by P. Brown.

Huang, R. X, 1993. Real freshwater flux as a natural boundary condition for the salinity balance and thermohaline circulation forced by evaporation and precipitation. J. Phys. Oc., 23, 2428-2446.

Hendy, I. L., J. P. Kennett, E. B. Roark, and B. L. Ingram, 2002. Apparent synchorneity of submillennial scale climate events between Greenland and Santa Barbara Basin, California from 20-10ka. Quat. Sci. Rev., 21, 1167-1184.

Hendy, I. L., T. F. Pedersen, J. P. Kennett and R. Tada, 2004. Intermittent existence of a southern Californian upwelling cell during submillennial climate change of the last 60kyr. Paleoceanog., 19, doi:10.1029/2003PA000965.

Jackson, C., Sensitivity of stationary wave amplitude to regional changes in Laurentide ice sheet topography in single-layer models of the atmosphere. J. Geophys. Res., 105. 24,44324,454, .

Jouzel, R. B. Alley, K. M. Cuffey, W. Dansgaard, P. Grootes, G. Hoffmann, S. J. Johnsen, R. D. Koster, D. Peel, C. A. Shuman, M. Stievenard, M. Stuiver and J. White, 1997. Validity of the temperature reconstruction from water isotopes in ice cores. J. Geophys. Res., 102, $26,471-26,487$.

Justino, F. A. Timmermann, U. Merkel, and E. P. Souza, 2005.Synoptic reorganization of atmospheric flow during the last glacial maximum. J. Clim., 18, 2826-2846

Kahneman, D., P. Slovic, A. Tversky, 1982. Judgment Under Uncertainty: Heuristics and Biases. 555pp.Cambridge Un. Press, Cambridge

Kalnay, E. and 21 others, 1996. The NCEP/NCAR 40-year reanalysis project. Bull. Am. Met. Soc., 77, 437-471.

Kutzbach, J. E. and P. E. Guetter, 1986. The influence of changing orbital parameters and surface boundary conditions on climate simulations for the past 18,000 years. J. Atm. Scis., 43, 1726-1759.

Landais, A., J. M. Barnola, V. Masson-Delmotte, J. Jouzel, J. Chappellaz, N. Caillon, C. 
Huber, M. Leuenberger, and S. J. Johnsen, 2004. A continuous record of temperature evolution over a sequence of Dansgaard-Oeschger events during Marine Isotope Stage 4 (76 to 62kyr BP). Geophys. Res. Letts., 31, doi:10.1029/2004GL021193.

Large, W. G., J. C. McWilliams, and S. C. Doney, 1994. Oceanic vertical mixing: a review and a model with nonlocal boundary layer parameters. Revs. Geophys., 32, 363-403.

Larsen, G. C. W. Bierbooms and K. S. Hansen, 2003. Statistics of Local Extremes. Riso/R-1220 (EN) Riso/ National Laboratory, Roskilde, Denmark, 62pp.

Li, C., D. S. Battisti, D. P. Schrag and E. Tziperman, 2005. Abrupt climate shifts in Greenland due to displacements of the sea ice edge. Geophys. Res. Letts., 32, doi:10.1029/2005GL023492.

Manabe, S. and R. J. Stouffer, 1999. Are two modes of thermohaline circulation stable? Tellus, 51A, 400-411.

Moore, M. I. and P. J. Thomson, 1991. Impact of jittered sampling on conventional spectral estimates. J. Geophys. Res., 96, 18,519-18,526.

Munk, W. and C. Wunsch, 1998. Abyssal recipes II: energetics of tidal and wind mixing. Deep-Sea Res., 45, 1976-2009.

Neelin, J. D. D. S. Battisti, A. C. Hirst, F.-F. Jin, Y. Wakata, T. Yamagata, and S. E. Zebiak, 1998. ENSO Theory. J. Geophys. Res., 103, 14,621-14,290.

Newman, W. I., M. P. Haynes and Y. Terzian, 1994. Redshift data and statistical inference. Ap. J., 431, 147-155.

Nilsson, J., G. Broström, G. Walin, 2003. The thermohaline circulation and vertical mixing: does weaker density stratification give stronger overturning? J. Phys. Oc., 33, 2781-2795.

Pedlosky, J., 1996. Ocean Circulation Theory. Springer-Verlag, Berlin, 450 pp.

Peltier, W. R., 1994. Ice age paleotopography. Science, 265, 195-201.

Peltier, W. R., 1995. Paleotopography of glacial-age ice sheets - Reply. Science, 267, 536-538.

Peterson, L. C. G. H. Haug, K. A. Hughen, U. Röhl, 2000. Rapid changes in the hydrologic cycle of the tropical Atlantic during the last glacial. Science, 290, 1947-1951.

Price, J. F., R. A. Weller, and R. Pinkel, 1986. Diurnal cycling: obswervations and modls of the upper ocean response to diurnal heat, cooling, and wind mixing. J. Geophys. Res., 91, 8411-8427.

Roe, G. H. and R. S. Lindzen, 2001. The mutual interaction between continental-scale ice sheets and atmospheric stationary waves. J. Clim., 14, 1450-1465.

Schiermeier, Q., 2004. Gulf Stream probed for early warnings of system failure. Nature, 427, 769 .

Schmittner, A., 2005. Decline of the marine ecosystem caused by a reduction in the Atlantic overturning circulation. Nature, 434, 628-633. 
Schulz, H., U. von Rad, H. Erlenkeuser, 1998. Correlation between Arabian Sea and Greenland climate oscillations of the past 110,000 years. Nature, 393, 54-57.

Severinghaus, J. P. and E. J. Brook, 1999. Abrupt climate change at the end of the last glacial period inferred from trapped air in polar ice. Science, 286, 930-934.

Severinghaus, J. P. T. Sowers, E. J. Brook, R. B. Alley, and M. L. Bender, 1998. Timing of abrupt climate change at the end of the Younger Dryas interval from thermally fractionated gases in polar ice. Nature, 391, 141-146.

Stone, P. H., 1978. Constraints on dynamical transports of energy on a spherical planet. Dyn. Atm. Oceans. 2, 123-139.

Stuiver, M. and P. M. Grootes, 2000. GISP2 oxygen isotope ratios. Quat. Res., 53, 277-284.

Vanmarcke, E., 1983. Random Fields: Analysis and Synthesis. The MIT Press, Cambridge, 382 pp.

Wang, Y. J., H. Cheng, R. L. Edwards, Z. S. An, J. Y. Wun, C. C. Shen and J. A. Dorale, 2001. A high-resolution absolute-dated Late Pleistocene monsoon record from Hulu Cave. Science, 294, 2345-2348.

Wunsch, C. and R. Ferrari, 2004. Vertical Mixing, Energy, and the General Circulation of the Oceans. Ann. Revs. Fl. Mech., 36, doi:10.1146/annurev.fluid.36.050802.122121.

Wunsch, C. and D. E. Gunn, 2003. A densely sampled core and climate variable aliasing. Geo-Mar. Letts., 23(1),DOI: 10.1007/s00367-003-0125-22003.

Wunsch, C., 2000. On sharp spectral lines in the climate record and the millennial peak. Paleoceanog., 15, 417-424.

Wunsch, C., 2002. What is the thermohaline circulation? Science, 298, 1180-1181.

Wunsch, C., 2003. Greenland-Antarctic phase relations and millennial time-scale fluctuations in the Greenland cores,. Quat. Sci. Revs., 22/15-17, 1631-1646.

Wunsch, C., 2003. Determining paleoceanographic circulations, with emphasis on the Last Glacial Maximum. Quat. Sci. Revs., 22/2-4, 371-385.

Wunsch, C., 2005. The total meridional heat flux and its oceanic and atmospheric partition. J. Clim., 18, 4374-4380, 2005.

Yu, E.-F., R. François and M. P. Bacon, 1996. Similar rates of modern and last-glacial ocean thermohaline circulation inferred from radiochemical data. Nature, 379, 689-694. 


\section{Figure Captions}

1. $\delta^{18} \mathrm{O}$ from the GISP2 ice core as measured in the Quaternary Research Laboratory, U. of Washington (Stuiver and Grootes, 2000). Note that time runs from left to right in the historical convention. The ratio of ${ }^{18} \mathrm{O}$ to ${ }^{16} \mathrm{O}$ concentrations is believed to track local atmospheric temperatures in central Greenland to within an approximate factor of two (e.g., Landais et al., 2004). Large positive spikes are called Dansgaard-Oeschger (D-O) events and are correlated with abrupt warmings - measured independently in some cases. Note in particular, the quiescence of the Holocene interval (approximately the last 10,000 years) relative to the preceding glacial period. The Holocene coincides with the removal of the Laurentide and Fennoscandian ice sheets. Age model is by layer counting back to about 30,000 years and is model-based prior to that time. The range of excursion is believed to correspond to about $15^{\circ} \mathrm{C}$.

2. Black curve is the maximum monthly temperature in Oxford England 1861-1903, and the gray curve from 1936-1978. The annual cycle was first removed from the entire record, and a three month running average was then formed and plotted, with the two intervals arbitrarily chosen. Although there is a strong visual similarity between the records, with identifiable corresponding peaks and troughs, it is a consequence simply of their common spectral content and hence statistics of zero crossing. The sample correlation of the two records is 0.4 , but is not statistically significant. It could be greatly increased by adjusting the relative time bases of the records. For use of the Rice statistics described in the text, one would first remove the record averages.

3. Time series of green-band reflectance in the Cariaco Basin (black) as reported by Peterson et al. (2000) and of $\delta^{18} \mathrm{O}$ from GISP2 (gray) reported by Stuiver and Grootes (2000; cf. Fig. ??). The Cariaco curve has been displaced upward by 6 units. Time runs from left to right. Some features appear common, as one would expect from the manual tuning that was done by Peterson et al. (2000), but some features appearing in one curve do not appear in the other. Whether the similar features are more important to understanding than the dis-similarities is not so clear. Note that the dominant phase between the records is $180^{\circ}$ so that fluctuations tend to have the opposite sign.

4. Coherence estimate with a 95\% level of no significance for amplitude (upper panel, dashed line) and with a $95 \%$ confidence interval for the phase (lower panel) between the Cariaco Basin

reflectance and GISP2 $\delta^{18} \mathrm{O}$. Negative of reflectance was used to render the low frequency phase near $0^{\circ}$ rather than $180^{\circ}$ which causes artificial plotting jumps between $\pm 180^{\circ}$. 
5. Estimated power density spectra of the Cariaco Basin reflectance data (black), and of the $\delta^{18} \mathrm{O}$ results (gray) of Stuiver and Grootes (2000) as used by Peterson et al. (2000). The spectral shapes are similar but not identical. The degree of aliasing in these records remains unknown, although Wunsch (2000) has suggested that it is significant in the Greenland core. An estimated $95 \%$ confidence interval is shown. Ratios of the low order moments of these spectra are numerically very close.

6. Identification of supposedly corresponding events in the Hulu Cave record and in Greenland ice core (re-drawn from Alley, 2005). Notice, e.g., that the large excursions in the Hulu cave record near $-45 \mathrm{KY}$ and $-30 \mathrm{KY}$ have no counterpart in the Greenland record.

7. (Re-drawn from Hendy et al., 2002) showing the apparent correspondence between the $\delta^{18} \mathrm{O}$ record in Santa Barbara Basin and that in the GISP2 record. That an equivalent degree of high frequency variability exists in both records is evident; whether the oscillations actually correspond as the dashed lines indicate, is much less obvious. Note that Hendy et al. (2004) invoke local wind and ocean circulation effects to rationalize the Santa Barbara record.

8. Methane (black) and $\delta^{18} \mathrm{O}$ (gray) concentrations in the GRIP core from central Greenland. The curves have been divided by their standard deviations and their means removed to facilitate visual comparison. The $\delta^{18} \mathrm{O}$ curve has been displaced upwards for clarity. See Blunier and Brook, 2001.

9. Power densities (a, b) and coherences (c-f) for the GRIP $\mathrm{CH}_{4}$ and $\delta^{18} \mathrm{O}$ records. Both records were normalized to unit variance before computation so that the power densities are dimensionless power/cycle/KY. Coherence is plotted on both linear and logarithmic frequency scales. An approximate $95 \%$ confidence level of no significance for the coherence is shown as a dashed line. Coherence magnitudes are above the level-of-no-significance only at low frequencies.

10. Total meridional heat transport of the combined ocean/atmosphere system estimated from Earth Radiation Budget Experiment (ERBE) satellites (solid), direct ocean measurments (dashed), and atmospheric contribution as a residual (dash-dot line). Taken from Wunsch (2005a). Standard error bars are shown.

11. Absolute geostrophic velocity estimate at $7.5^{\circ} \mathrm{N}$ in a section across the North Atlantic Ocean (simplified from Ganachaud, 1999). Clear areas depict northward flows, stippled southward ones. To determine the flux of a particular property demands multiplying this field by the concentration distribution, and integrating zonally and vertically. An Ekman component in 
the upper, approximately, 100m is not shown here. See Ganachaud (1999) for a fully contoured version of this figure. Note only that the region near $2500 \mathrm{~m}$ on the far-west corresponds to the Deep Western Boundary Current, and near-surface flows there are also intensified relative to the interior.

12. Estimate of the extent of the northern hemisphere ice sheets through time. Times are BP. Simplified from Peltier (1994), and showing only one interior contour representing the highest elevation. Very large orographic and albedo changes are implied by the disappearance of the ice sheets in the Holocene as compared to the glacial period. Ice thickness over North America approached $3 \mathrm{~km}$ and the wind conditions in central Greenland are likely to be very different today than they were at the height of the glaciation. D-O events disappear around $-10 \mathrm{KY}$.

13. (From Roe and Lindzen, 2001). Observed January stationary wave. The National Centers for Environmental Prediction reanalysis data (Kalnay et al. 1996 ), average from 1980 to 1990. (a) The 500-mb geopotential heights (10-s of meters), and (b) perturbation of lowertropospheric temperature from the zonal mean $\left({ }^{\circ} \mathrm{C}\right)$, calculated by equating the $1000-500-\mathrm{mb}$ thickness to a vertical mean temperature.

14. Schematic of model geometry. The ice sheet is allowed to evolve on the rectangular continent within the channel domain of the atmospheric stationary wave model. The southern boundary of the channel is at a distance equivalent to a latitude of $90^{\circ} \mathrm{S}$. A radiation condition is applied at $z=20 \mathrm{~km}$. (See Roe and Lindzen, 2001, for further details.).

15. Global patterns of the stationary wave fields generated by the ice sheet in Fig. 14 as computed by Roe and Lindzen (2001). (a) Here $z=5-\mathrm{km}$ geopotential heights (dm), and (b) temperature perturbation from zonal mean at $z=1 \mathrm{~km}\left({ }^{\circ} \mathrm{C}\right)$. The forcing ice sheet is faintly outlined. The stationary wave pattern exerts a significant influence on climate both upstream and downstream of the forcing region. Feedbacks between ice and atmosphere modify the shape and volume of the ice sheet and lead to the possibility of abrupt shifts. 


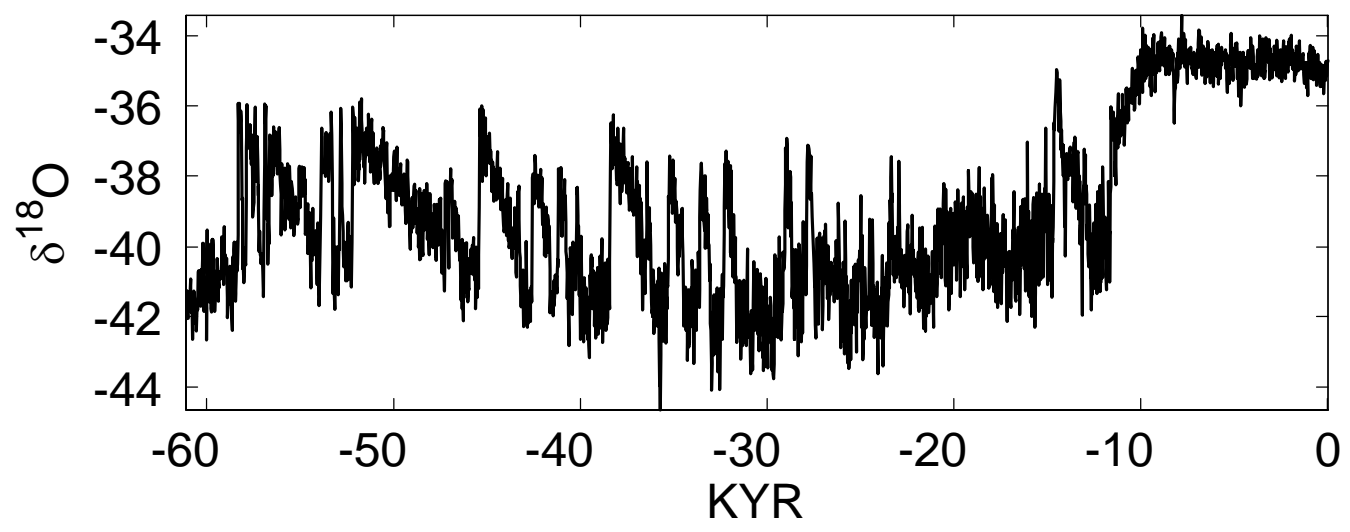

Figure 1: $\delta^{18} \mathrm{O}$ from the GISP2 ice core as measured in the Quaternary Research Laboratory, U. of Washington (Stuiver and Grootes, 2000). Note that time runs from left to right in the physics convention. The ratio of ${ }^{18} \mathrm{O}$ to ${ }^{16} \mathrm{O}$ concentrations is believed to track local atmospheric temperatures in central Greenland to within an approximate factor of two (e.g., Landais et al., 2004). Large positive spikes are called Dansgaard-Oeschger (D-O) events and are correlated with abrupt warmings - measured independently in some cases. Note in particular, the quiescence of the Holocene interval (approximately the last 10,000 years) relative to the preceding glacial period. The Holocene coincides with the removal of the Laurentide and Fennoscandian ice sheets. Age model is by layer counting back to about 30,000 years and is model-based prior to that time. The range of excursion is believed to correspond to about $15^{\circ} \mathrm{C}$. 


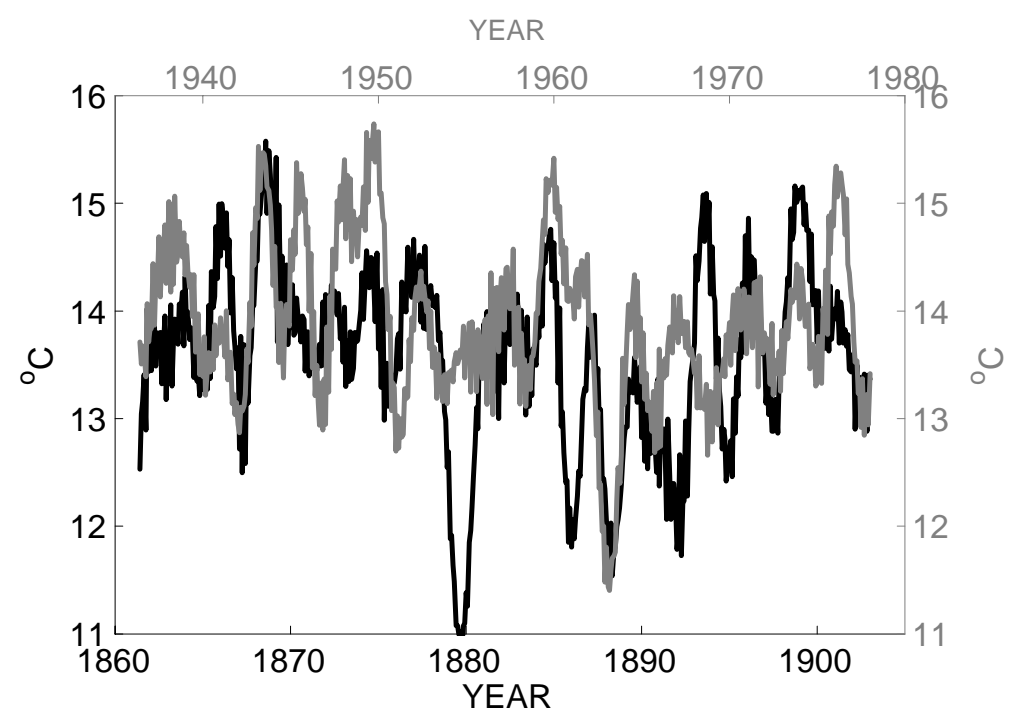

Figure 2: Black curve is the maximum monthly temperature in Oxford England 1861-1903, and the red curve from 1936-1978. The annual cycle was first removed from the entire record, and a three month running average was then formed and plotted, with the two intervals arbitrarily chosen. Although there is a strong visual similarity between the records, with identifiable corresponding peaks and troughs, it is a consequence simply of their common spectral content and hence statistics of zero crossing. The sample correlation of the two records is 0.4 , but is not statistically significant. It could be greatly increased by adjusting the relative time bases of the records. For use of the Rice statistics described in the text, one would first remove the record averages. 


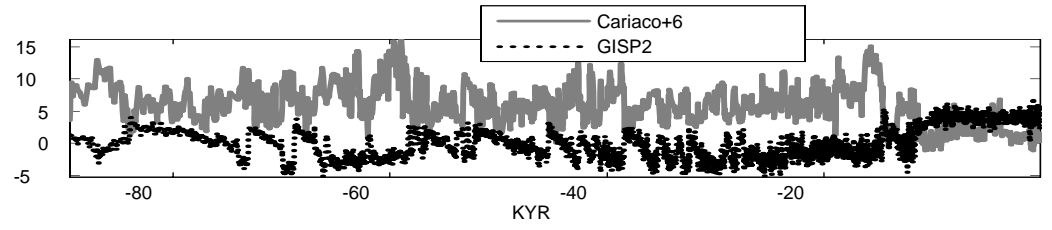

Figure 3: Time series of green-band reflectance in the Cariaco Basin (blue, solid curve) as reported by Peterson et al. (2000) and of $\delta^{18} \mathrm{O}$ from GISP2 reported by Stuiver and Grootes (2000; cf. Fig. 1). The Cariaco curve has been displaced upward by 6 units. Time runs from left to right. Some features appear common, as one would expect from the manual tuning that was done by Peterson et al. (2000), but some features appearing in one curve do not appear in the other. Whether the similar features are more important to understanding than the dissimilarities is not so clear. Note that the dominant phase between the records is $180^{\circ}$ so that fluctuations tend to have the opposite sign.
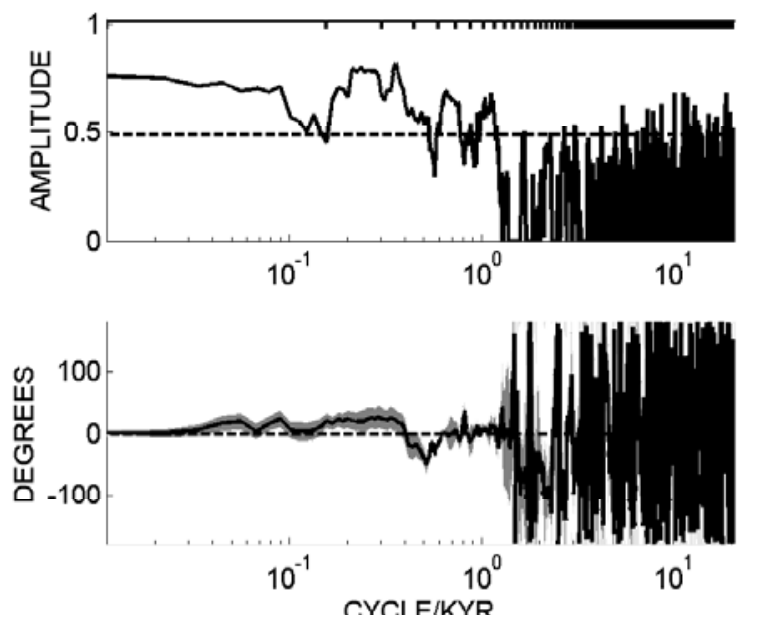

Figure 4: Coherence estimate with a 95\% level of no significance for amplitude (upper panel, dashed line) and with a $95 \%$ confidence interval for the phase (lower panel) between the Cariaco Basin reflectance and GISP2 $\delta^{18} \mathrm{O}$. Negative of reflectance was used to render the low frequency phase near $0^{\circ}$ rather than $180^{\circ}$ which causes artificial jumps between $\pm 180^{\circ}$. 


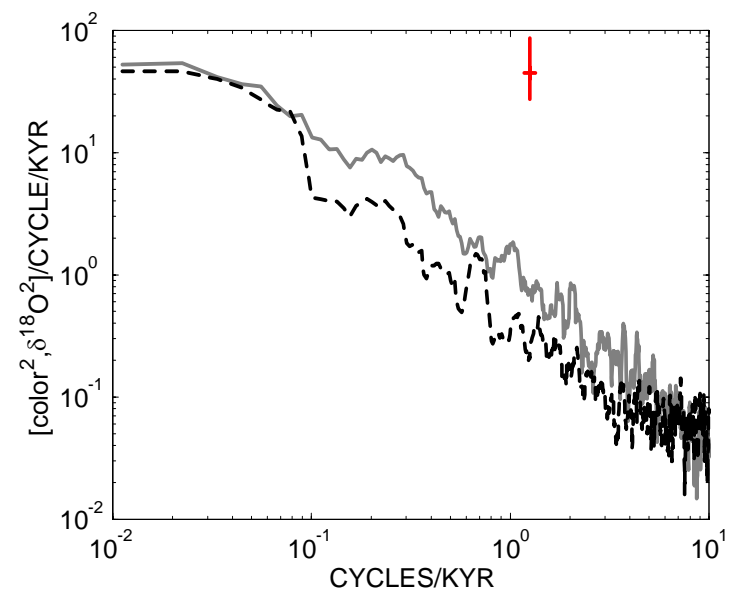

Figure 5: Estimated power density spectra of the Cariaco Basin reflectance data (blue-solid curve), and of the $\delta^{18} \mathrm{O}$ results (red-dotted curve) of Stuiver and Grootes (2000) as used by Peterson et al. (2000). The spectral shapes are similar but not identical, particularly at high frequencies where the differing original sampling intervals distort the results. The degree of aliasing in these records remains unknown, although Wunsch (2000) has suggested that it is significant in the Greenland core. An estimated $95 \%$ confidence interval is shown. Ratios of the low order moments of these spectra are numerically very close. 


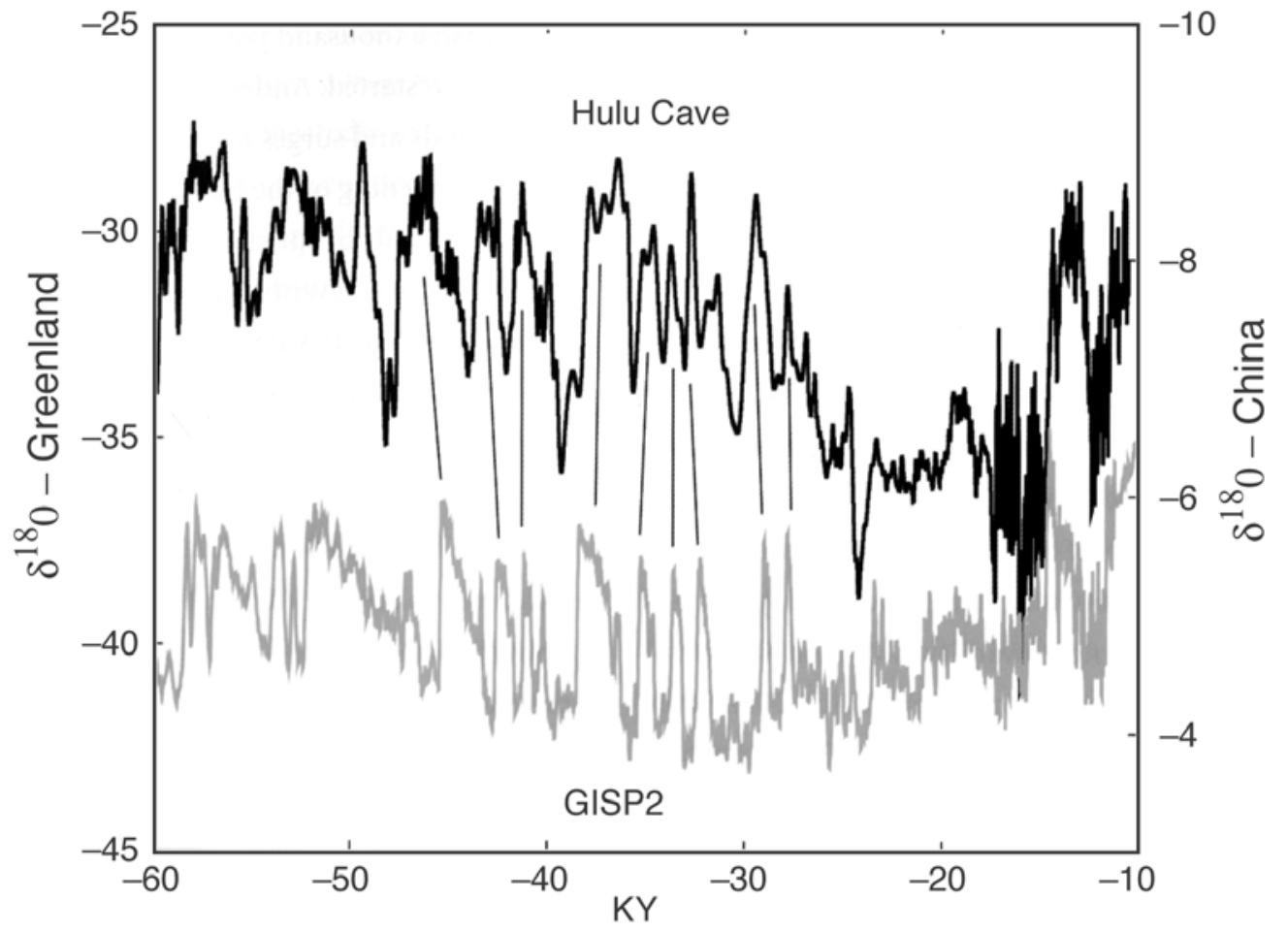

Figure 6: Identification of supposedly corresponding events in the Hulu Cave record and in Greenland ice core (re-drawn from Alley, 2005). Notice, e.g., that the large excursions in the Hulu cave record near $-45 \mathrm{KY}$ and $-30 \mathrm{KY}$ have no counterpart in the Greenland record. 


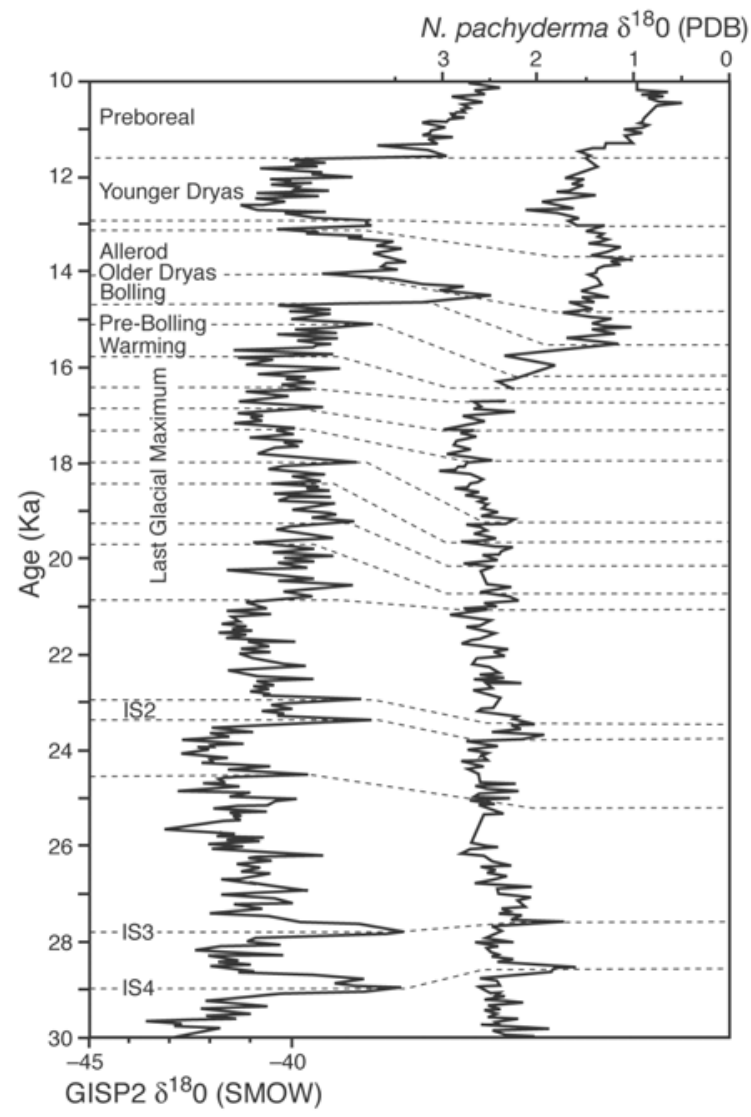

Figure 7: (Re-drawn from Hendy et al., 2002) showing the apparent correspondence between the $\delta^{18} \mathrm{O}$ record in Santa Barbara Basin and that in the GISP2 record. That an equivalent degree of high frequency variability exists in both records is evident; whether the oscillations actually correspond as the dashed lines indicate, is much less obvious. Note that Hendy et al. (2004) invoke local wind and ocean circulation effects to rationalize the Santa Barbara record. 


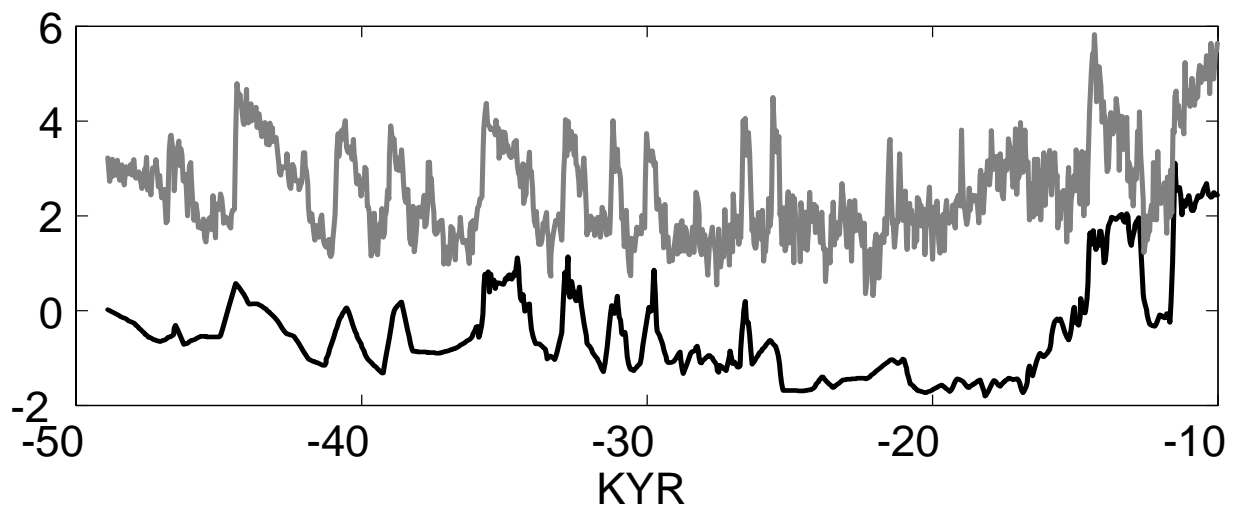

Figure 8: Methane (solid) and $\delta^{18} \mathrm{O}$ concentrations in the GRIP core from central Greenland. The curves have been divided by their standard deviations and their means removed to facilitate visual comparison. The $\delta^{18} \mathrm{O}$ curve has been displaced upwards for clarity. 

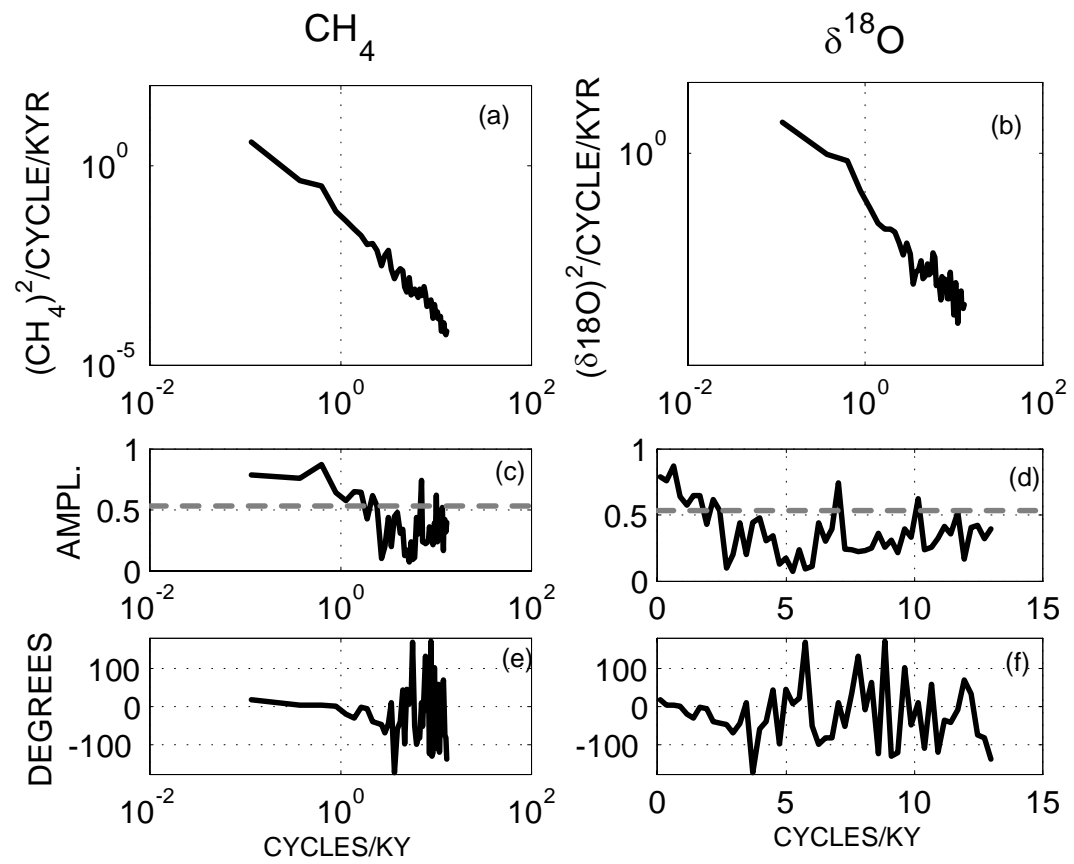

Figure 9: Power densities (a, b) and coherences (c-f) for the GRIP $\mathrm{CH}_{4}$ and $\delta^{18} \mathrm{O}$ records. Both records were normalized to unit variance before computation so that the power densities are dimensionless power/cycle/KY. Coherence is plotted on both linear and logarithmic frequency scales. An approximate $95 \%$ confidence level of no significance for the coherence is shown as a dashed line. Coherence magnitudes are above the level-of-no-significance only at low frequencies. 


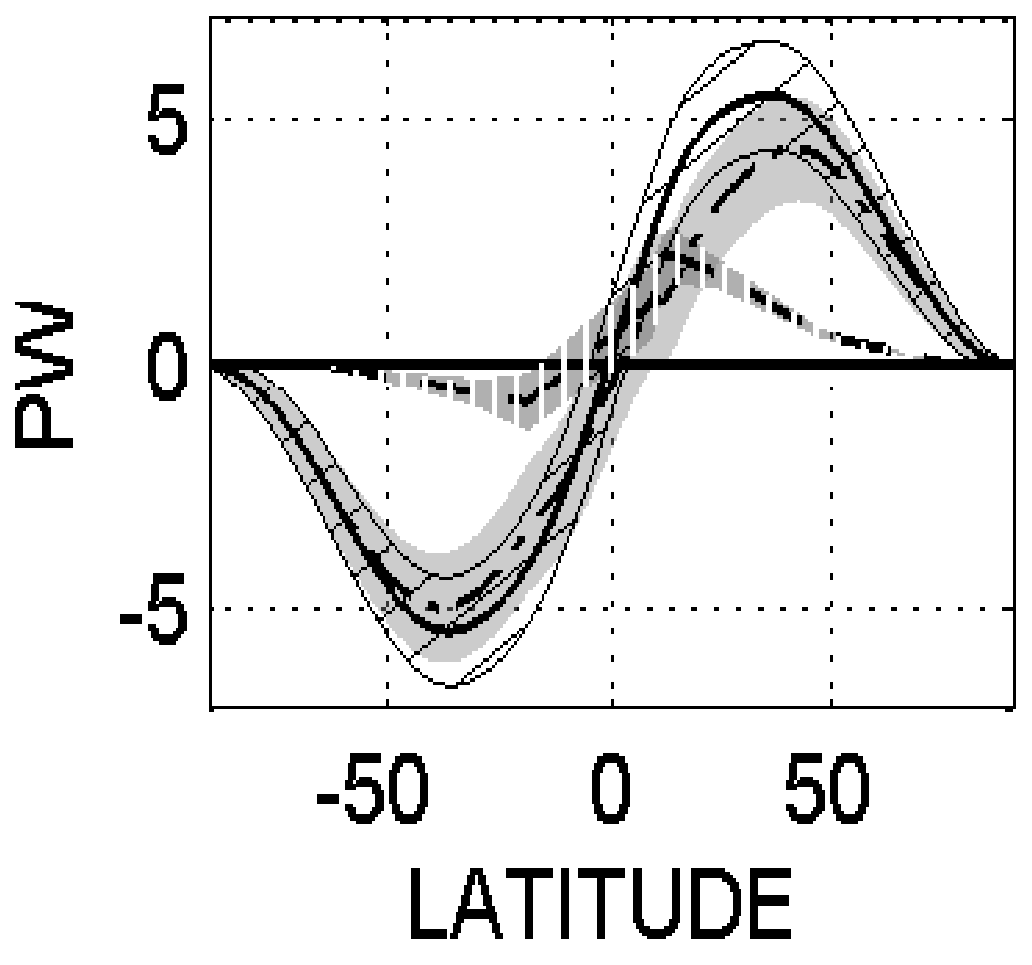

Figure 10: Total meridional heat transport of the combined ocean/atmosphere system estimated from Earth Radiation Budget Experiment (ERBE) satellites (solid), direct ocean measurments (dashed), and atmospheric contribution as a residual (dash-dot line). Taken from Wunsch (2005a). Estimated error bars are one-standard deviation. 


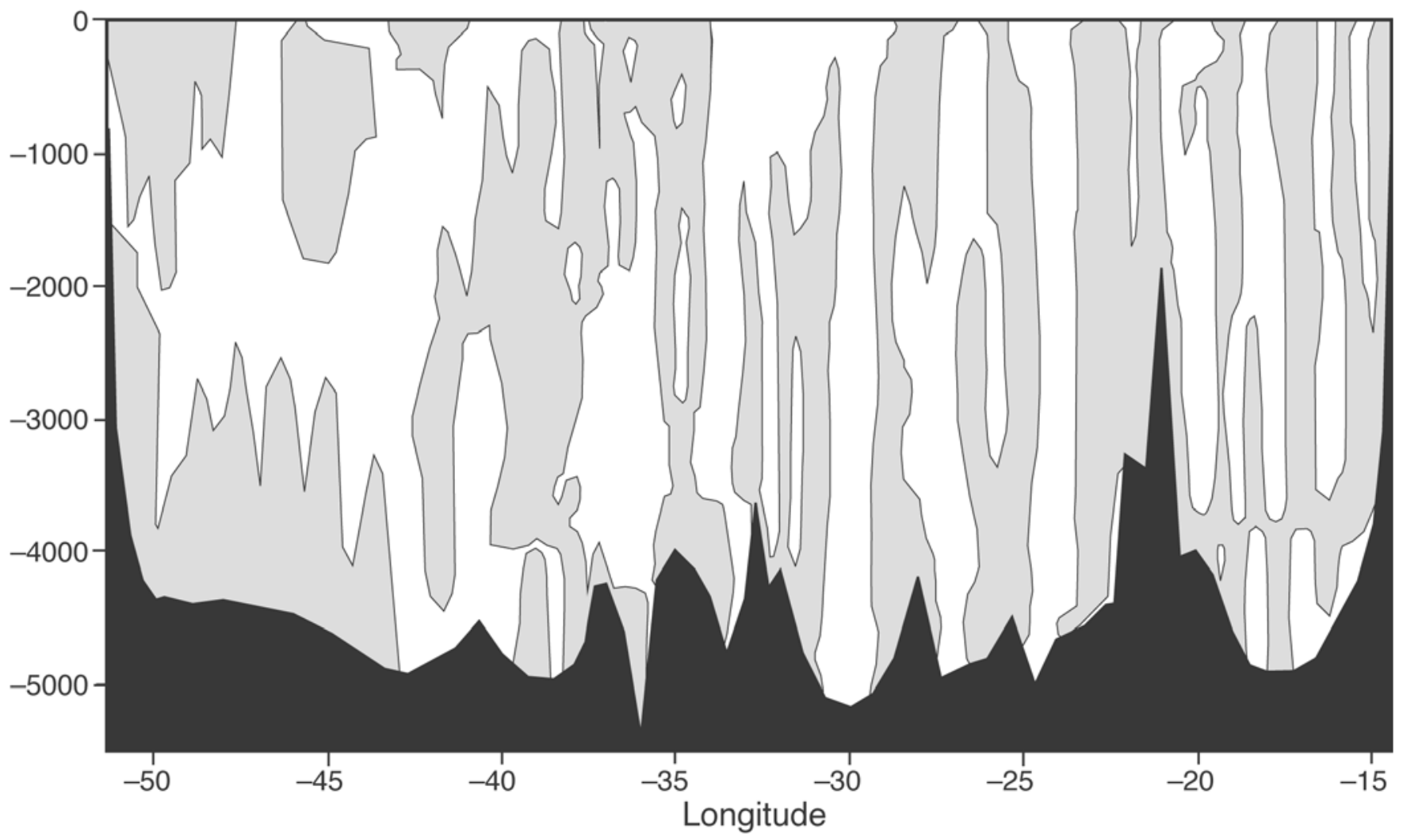

Figure 11: Absolute geostrophic velocity estimate at $7.5^{\circ} \mathrm{N}$ in a section across the North Atlantic Ocean (simplified from Ganachaud, 1999). Clear areas depict northward flows, stippled southward ones. To determine the flux of a particular property demands multiplying this field by the concentration distribution, and integrating zonally and vertically. An Ekman component in the upper, approximately, 100m is not shown here. See Ganachaud (1999) for a fully contoured version of this figure. Note only that the region near $2500 \mathrm{~m}$ on the far-west corresponds to the Deep Western Boundary Current, and near-surface flows there are also intensified relative to the interior. 


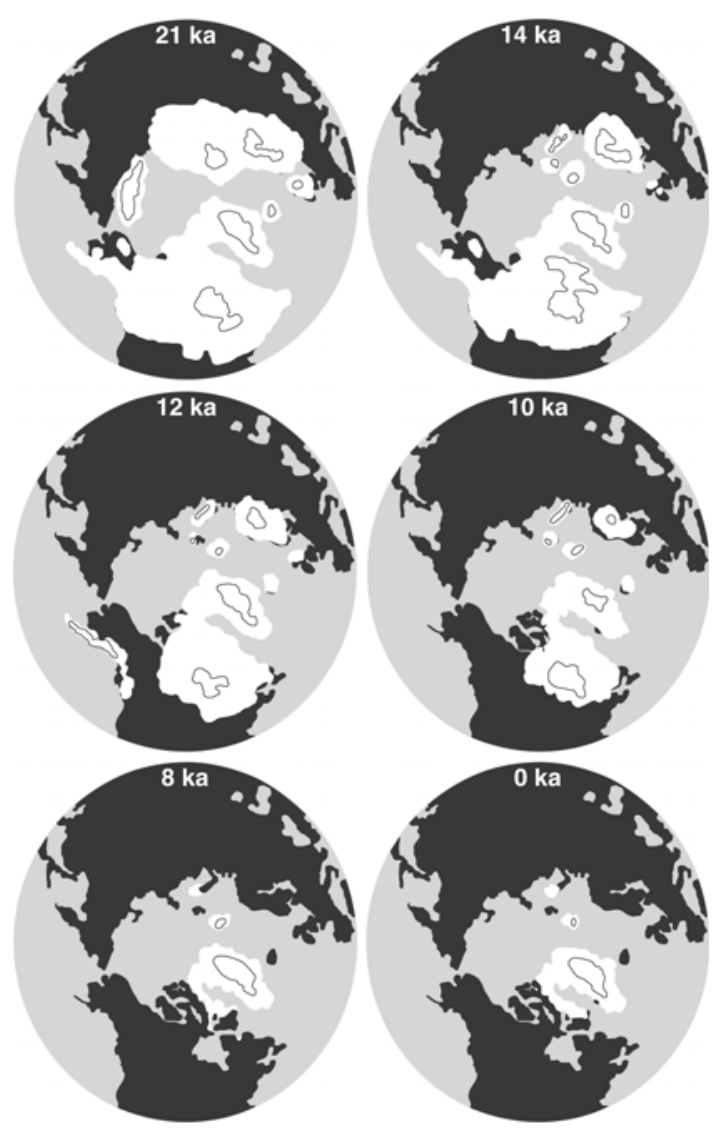

Figure 12: Estimate of the extent of the northern hemisphere ice sheets through time. Times are BP. Simplified from Peltier (1994), and showing only one interior contour representing the highest elevation. Very large orographic and albedo changes are implied by the disappearance of the ice sheets in the Holocene as compared to the glacial period. Ice thickness over North America approached $3 \mathrm{~km}$ and the wind conditions in central Greenland are likely to be very different today than they were at the height of the glaciation. D-O events disappear around $-10 \mathrm{KY}$. 
Schematic of model geometry

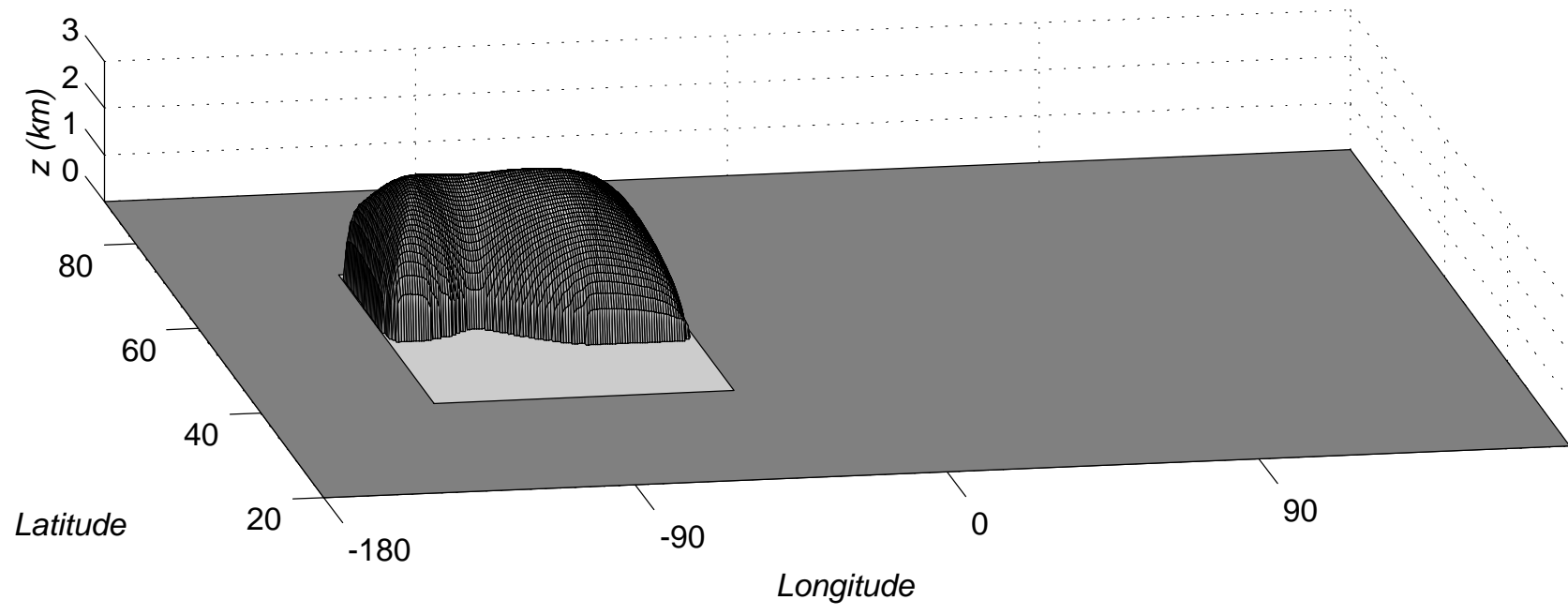

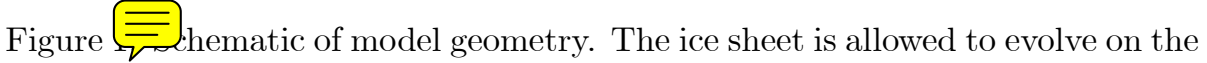
rectangular continent within the channel domain of the atmospheric stationary wave model. The southern boundary of the channel is at a distance equivalent to a latitude of $90^{\circ} \mathrm{S}$. A radiation condition is applied at $\mathrm{z}=20 \mathrm{~km}$. (See Roe and Lindzen, 2001, for further details.). 

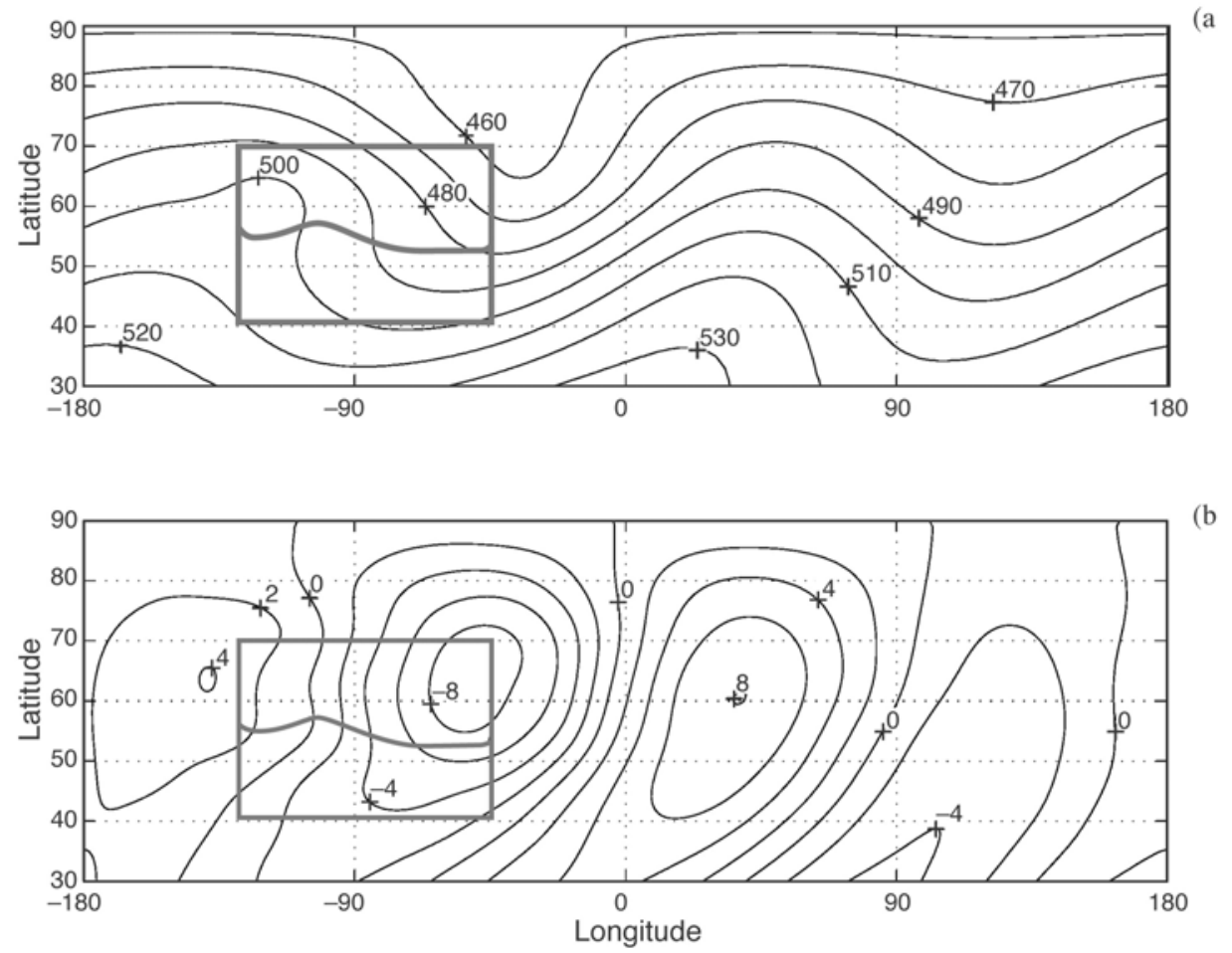

Figure $\equiv$ Ilobal patterns of the stationary wave fields generated by the ice sheet in Fig. 8 as computed by Roe and Lindzen (2001). (a) Here $z=5-\mathrm{km}$ geopotential heights $(\mathrm{dm})$, and (b) temperature perturbation from zonal mean at $\mathrm{z}=1 \mathrm{~km}\left({ }^{\circ} \mathrm{C}\right)$. The forcing ice sheet is faintly outlined. The stationary wave pattern exerts a significant influence on climate both upstream and downstream of the forcing region. Feedbacks between ice and atmosphere modify the shape and volume of the ice sheet and lead to the possibility of abrupt shifts. 